\title{
Reciprocal Synapses Between Outer Hair Cells and their Afferent Terminals: Evidence for a Local Neural Network in the Mammalian Cochlea
}

\author{
Fabio A. Thiers, ${ }^{1,2,3}$ Joseph B. Nadol Jr., ${ }^{2,3}$ And M. Charles Liberman ${ }^{1,2,3}$ \\ ${ }^{1}$ Eaton-Peabody Laboratory, Massachusetts Eye and Ear Infirmary, 243 Charles Street, Boston, MA, USA \\ ${ }^{2}$ Department of Otology and Laryngology, Harvard Medical School, Boston, MA 02114, USA \\ ${ }^{3}$ Program in Speech and Hearing Bioscience and Technology, Division of Health Science and Technology, Harvard $\mathcal{E}$ MIT, \\ Cambridge, MA, USA
}

Received: 9 May 2008; Accepted: 14 July 2008; Online publication: 8 August 2008

\begin{abstract}
Cochlear outer hair cells (OHCs) serve both as sensory receptors and biological motors. Their sensory function is poorly understood because their afferent innervation, the type-II spiral ganglion cell, has small unmyelinated axons and constitutes only $5 \%$ of the cochlear nerve. Reciprocal synapses between OHCs and their type-II terminals, consisting of paired afferent and efferent specialization, have been described in the primate cochlea. Here, we use serial and semi-serial-section transmission electron microscopy to quantify the nature and number of synaptic interactions in the $\mathrm{OHC}$ area of adult cats. Reciprocal synapses were found in all OHC rows and all cochlear frequency regions. They were more common among third-row OHCs and in the apical half of the cochlea, where $86 \%$ of synapses were reciprocal. The relative frequency of reciprocal synapses was unchanged following surgical transection of the olivocochlear bundle in one cat, confirming that reciprocal synapses were not formed by efferent fibers. In the normal ear, axo-dendritic synapses between olivocochlear terminals and type-II terminals and/or dendrites were as common as synapses between olivocochlear terminals and OHCs, especially in the first row, where, on average, almost 30 such synapses were seen in the region under a single OHC. The results suggest that a complex local neuronal circuitry in the OHC area,
\end{abstract}

Correspondence to: M. Charles Liberman · Eaton-Peabody Laboratory • Massachusetts Eye and Ear Infirmary - 243 Charles Street, Boston, MA 02114. Telephone: +1-617-5733745; fax: +1-617-7204408; email: Charles_Liberman@meei.harvard.edu formed by the dendrites of type-II neurons and modulated by the olivocochlear system, may be a fundamental property of the mammalian cochlea, rather than a curiosity of the primate ear. This network may mediate local feedback control of, and bidirectional communication among, OHCs throughout the cochlear spiral.

Keywords: inner ear, auditory nerve, spiral ganglion

\section{INTRODUCTION}

Mammalian outer hair cells (OHCs) serve a dual function: as sensory receptors, transducing sound-evoked vibrations into electrical signals, and as biological motors, reverse-transducing these electrical signals into mechanical motion to amplify cochlear vibrations (Dallos and Fakler 2002). OHCs are innervated by terminals of the olivocochlear (OC) bundle (Kimura and Wersall 1962), a feedback system, which can modulate the gain of the cochlear amplifier (Guinan 1996), and by the peripheral terminals of type-II spiral ganglion cells (Kiang et al. 1982), which send central axons to the cochlear nucleus (Brown et al. 1988).

Despite insights into the motor function of OHCs, little is known about their sensory role because type-II spiral ganglion cells comprise only $5-10 \%$ of the auditory nerve (Spoendlin 1972), and their central and peripheral axons are small and unmyelinated (Kiang et al. 1982). Thus, single-fiber recordings from type-II neurons are rare (Brown 1994; Robertson et al. 1999), and little is known about transmission at OHC/type-II synapses, 
except that it probably does not involve the same AMPAtype glutamate receptors at type-I synapses on inner hair cells (Matsubara et al. 1996; Pujol and Puel 1999).

Synapses between OHCs and their afferent terminals appear less robust than those at the IHC (Dunn and Morest 1975), where a prominent pre-synaptic ribbon with its halo of synaptic vesicles is almost always present (Liberman 1980b; Khimich et al. 2005; Stamataki et al. 2006). In contrast, ribbons are usually absent in adult OHCs (Dunn and Morest 1975; Liberman et al. 1990), and the OHC/type-II synapse is defined only by a small cluster of pre-synaptic vesicles and a small plaque of modest pre- and post-synaptic membrane thickening (Liberman et al. 1990).

Ultrastructural studies have shown reciprocal synapses between type-II terminals and their OHC contacts (Nadol 1981; Francis and Nadol 1993; Thiers et al. 2002b), in which a classic "afferent" synapse, with its vesicle cluster in the $\mathrm{OHC}$, is paired with an "efferent" synapse from the same terminal, characterized by a vesicle cluster in the type-II terminal positioned opposite a subsynaptic cistern in the OHC. This subsynaptic cistern is similar morphologically to that opposite classical efferent synapses from the vesicle-filled terminals of the olivocochlear bundle, which also project to the bases of OHCs (Kimura and Wersall 1962). These reciprocal synapses could mediate bidirectional signaling, and, given the extensive branching of type-II projections in the OHC area (Simmons and Liberman 1988a), such bidirectional signaling would constitute a local neural network through which OHCs communicate with each other over essentially the entire cochlear spiral, without engaging the central nervous system or the olivocochlear efferent pathway. However, reciprocal synapses in the $\mathrm{OHC}$ area have only been described in human (Nadol 1981; Thiers et al. 2002b) and chimpanzee (Francis and Nadol 1993) and in a neonatally de-efferented cat (Pujol and Carlier 1982), where their presence was viewed as an anomaly resulting from the loss of olivocochlear innervation.

In the present study, we used serial-section electron microscopy to show that such reciprocal synapses are as prevalent among OHC/type-II contacts in the normal cat cochlea as in the primate. Thus, bidirectional signaling throughout the OHC area may be a fundamental feature of the mammalian inner ear, rather than a curious specialization of the primate. Adding to the complexity of the neural circuitry in the OHC area, we also document an extensive direct innervation of the type-II system by olivocochlear efferent terminals.

\section{METHODS}

Three cochleas from three cats were used for the ultrastructural analysis. Two cats were from control animals, which, as part of previous physiological studies (Liberman 1978; Liberman and Beil 1979), underwent single-fiber recordings from the auditory nerve and had normal responses at all frequency regions [data from MCL94L (Fig. 3 in Liberman 1978) and MCL109L (Fig. 3 in Liberman 1978; Liberman and Beil 1979)]. Another cat, \# 93042L, underwent unilateral surgical de-efferentation during the first post-natal week, as described elsewhere (Liberman et al. 2000). All animal procedures were approved by the IACUC of the Massachusetts Eye and Ear Infirmary. Tissues procured prior to 1980 (when institutional animal care committees were not yet in existence) was done so according to procedures that have subsequently been approved by the local IACUC.

All animals were perfused intravascularly with $2.5 \%$ glutaraldehyde and $1.5 \%$ paraformaldehyde in $0.065 \mathrm{M}$ phosphate buffer at $\mathrm{pH} 7.3$, followed by intralabyrinthine perfusion of the same fixative and post-fixation at $4^{\circ} \mathrm{C}$ for several days. After post-fixation, cochleas were perfused with $1 \%$ osmium tetroxide for $1 \mathrm{~h}$ and then rinsed, dehydrated, and embedded in epoxy resins. After polymerization, cochleas were drilled down, and dissected partial turns of the organ of Corti were reembedded, thinned, and mounted on slides for lightmicroscopic evaluation. Cochlear lengths were measured by computerized planimetry and a frequency map computed for each ear (Liberman 1982).

The completeness of de-efferentation was assessed by measuring the summed diameters of efferent fascicles crossing to the OHC region through the tunnel of Corti using high-N.A. objectives and Nomarski optics. Efferent fibers are distinguished from afferents by their position in the tunnel. These data were obtained in osmiumstained cochlear whole mounts at 12 evenly spaced locations along from the cochlear spiral: Diameter measurements of all tunnel-crossing efferents in one microscopic field from each location were compared among a group of control and surgically de-efferented ears (Liberman et al. 2000). Previous work showed that this metric is well correlated with the volume of olivocochlear terminals remaining on OHCs (Liberman and Gao 1995).

For electron microscopy, selected whole mounts in regions of interest were removed from the slides, trimmed, and mounted on epon blanks for serial sectioning in one of two orientations (Fig. 1): parallel to the long axes of OHCs (longitudinal) or parallel to the cuticular plate (horizontal). Section ribbons were harvested on Formvar-coated slot grids, stained with uranyl acetate and lead citrate, and examined either on a Philips CM10 or a JEOL 100CX. For each sectioned block of tissue, a subset of the OHCs in each row was selected for analysis. In MCL94L, blocks from the 0.7- and $1.6-\mathrm{kHz}$ regions were sectioned longitudinally, and micrographs were captured from (1) every (serial) section at an overall magnification of $\times 29,000$ for the 


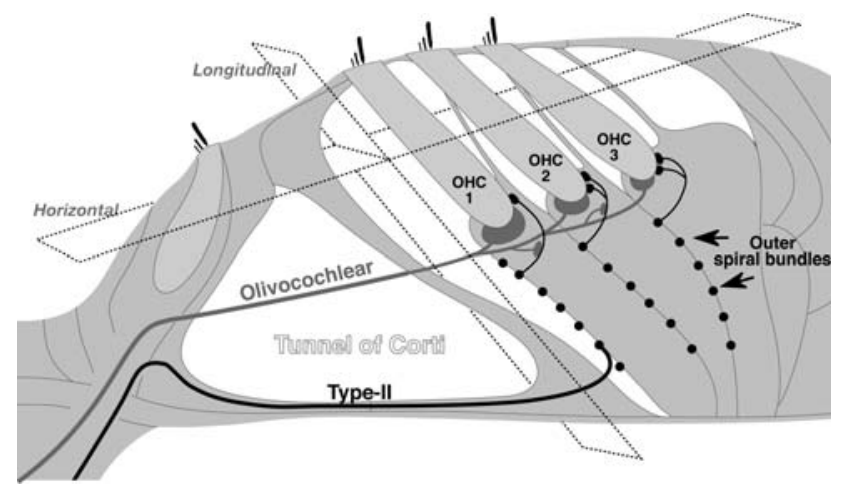

FIG. 1. Schematic illustrating the projections of type-II spiral ganglion cells and medial olivocochlear $(O C$ neurons in the outer hair cell $(\mathrm{OHC})$ area of a typical mammalian ear, as well as the section planes used for serial-section ultrastructural analysis.

$0.7 \mathrm{kHz}$ region and (2) every fifth (semi-serial) section at a final magnification of $\times 12,000-13,500$ for the $1.6-\mathrm{kHz}$ region. For MCL109L, multiple blocks were selected to investigate different cochlear regions (i.e., 0.35, 0.75, 1.3, $3.2,6.3,12.0$, and $23.0 \mathrm{kHz}$ ). Sections were cut parallel to the reticular lamina, and micrographs were captured from every fifth section at a final magnification of $\times 12,000-13,500$. For the de-efferented ear, 93042L, a block from the $1.0-\mathrm{kHz}$ region was selected, sections were cut horizontally, and micrographs were captured from every fifth section at a final magnification of $\times 12,000$ 13,500 . For all the section series, neural elements were traced by labeling the photographic montages of each section in the series.

For immunohistochemistry, cochleas from CBA/CaJ mice (6-8 weeks) were extracted and fixed in chilled $4 \%$ paraformaldehyde for $10 \mathrm{~min}$ prior to dissection into half turns without decalcification. Cochlear pieces were blocked for $2 \mathrm{~h}$ at $4^{\circ} \mathrm{C}$ in $5 \%$ normal horse serum with $1 \%$ Triton $\mathrm{X}-100$ and then incubated overnight at $4^{\circ} \mathrm{C}$ in the primary antibodies (rabbit anti-GluR2/3 from Chemicon at 1:500 and mouse anti-CtBP2 from BD Transduction Labs at 1:200) diluted in 1\% normal horse serum with $1 \%$ Triton. Secondary antibody incubations followed: the first, overnight at $4^{\circ} \mathrm{C}$, included biotinylated donkey anti-mouse (1:200, Jackson ImmunoResearch) plus fluorescent-conjugated chicken anti-rabbit (AlexaFluor 488, Invitrogen, 1:1,000): the second, for $1 \mathrm{~h}$ at room temperature, included streptavidin-conjugated AlexaFluor 568 (Invitrogen, 1:1,000) plus a goat anti-chicken conjugated to AlexaFluor 488 (Invitrogen, 1:1,000).

\section{RESULTS}

Classifying and identifying the sources of synaptic terminals in the $\mathrm{OHC}$ area

Many electron-microscopic studies described two major types of synaptic terminals at the basal pole of OHCs: large vesicle rich and small, vesicle poor (e.g., Thiers et al. 2002b; Kimura and Wersall 1962; Hashimoto and Kimura 1987). The large, vesicle-rich terminals are typically opposite a membranous subsynaptic cistern in the apposing OHC (Kimura and Wersall 1962) and were assumed to be descending projections from the OC system; correspondingly, most of these large terminals disappear after cutting the OC bundle in the brainstem (Iurato et al. 1978; Pujol and Carlier 1982; Liberman and Gao 1995). The small, vesicle-poor terminals are occasionally apposed to vesicle-studded synaptic ribbons within the OHC (Liberman et al. 1990) and were assumed to connect via peripheral dendrites to the unmyelinated type-II spiral ganglion cells, one of the two major classes of primary sensory neurons in the cochlea (Kiang et al. 1982). The appearance of these two terminal types in the cat cochlea is illustrated by the micrographs in Figure 2A.

Subsequent light-microscopic studies of peripheral branching patterns, using whole-cell filling via neuronal tracers such as HRP, showed that the large OC terminals arise from radially directed terminal branchlets, which cross the middle of the tunnel of Corti and immediately give rise to a small cluster of five to ten endings on neighboring OHCs in all three rows (Liberman and Brown 1986; Brown 1987a). In contrast, the peripheral dendrite of a type-II spiral ganglion cell crosses at the floor of the tunnel and spirals towards the base of the cochlea in the outer spiral bundles while slowly rising towards the bases of the OHCs and ultimately giving rise to small terminals contacting ten to 100 OHCs, typically contacting cells from a single OHC row (Brown 1987b; Simmons and Liberman 1988a). As illustrated in Figure 2B and $\mathrm{C}$, these spiraling type-II dendrites are plentiful in the region under the OHCs and are particularly rich in neurotubules.

Identifying the sources of synaptic terminals is key to the interpretation of data from the present study; thus, we made careful measurements of size, vesicle content, and dendritic origins of a large population of terminals in a normal ear and then compared the results to that seen in a cochlea with surgical transection of the OC bundle in the brainstem. As shown in Figure 3, serialsection reconstruction of a sample of 258 terminals contacting $18 \mathrm{OHCs}$ from all three rows in the $0.7-\mathrm{kHz}$ region of one cat reveals a clear dichotomy between a population of small vesicle-poor terminals traceable to spiraling parent fibers and a population of larger, vesicle-rich terminals traceable to radially directed branches. Furthermore, a semi-serial-section analysis of OHCs from a similar frequency region in a surgically de-efferented cochlea showed that literally all of the large vesicle-rich population had disappeared. Micrographs comparing similar regions from a normal and a de-efferented ears are shown in Figure $4 \mathrm{~A}$ and B, respectively: A prior light-microscopic analysis of the 


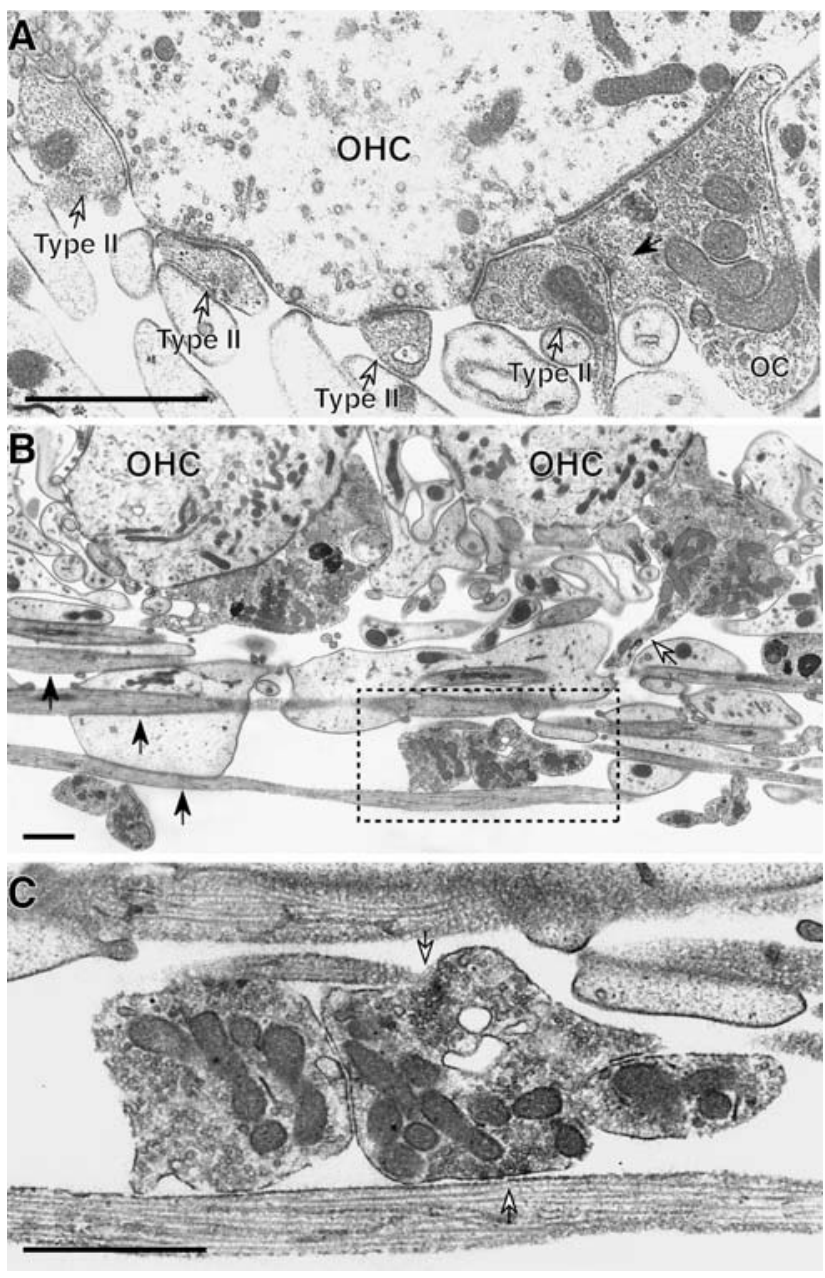

FIG. 2. Micrographs illustrating the terminals and unmyelinated peripheral dendrites of type-II and olivocochlear projections in the outer hair cell $(\mathrm{OHC})$ area cut in the longitudinal plane. A Synaptic pole of one first-row $\mathrm{OHC}$ from the $0.7-\mathrm{kHz}$ region showing several type-II terminals (open arrows), some opposite subsynaptic cisterns in the $\mathrm{OHC}$ and one with a synaptic contact from an adjacent $\mathrm{OC}$ terminal (filled arrow). B Region under the first row OHCs in the 0.7$\mathrm{kHz}$ region showing spiraling fibers (filled arrows) and radially directed fibers (unfilled arrow). C Close-up of the region indicated by the dashed box in B showing synapses between a vesicle-filled terminal and spiraling fibers (open arrows). Scale bars are $1 \mu \mathrm{m}$ in each panel.

tunnel-crossing fibers in this ear (Liberman et al. 2000) verified the extent of the de-efferentation throughout the cochlear spiral (Fig. 4C).

Based on this exhaustive morphometric analysis, we subsequently identified terminals as originating from either type-II or OC neurons on the basis of their size, vesicle content, and connection to radial vs. spiral dendrites.

\section{Prevalence of reciprocal synapses in cat}

Previous ultrastructural work in human and non-human primates described reciprocal synapses between type-II

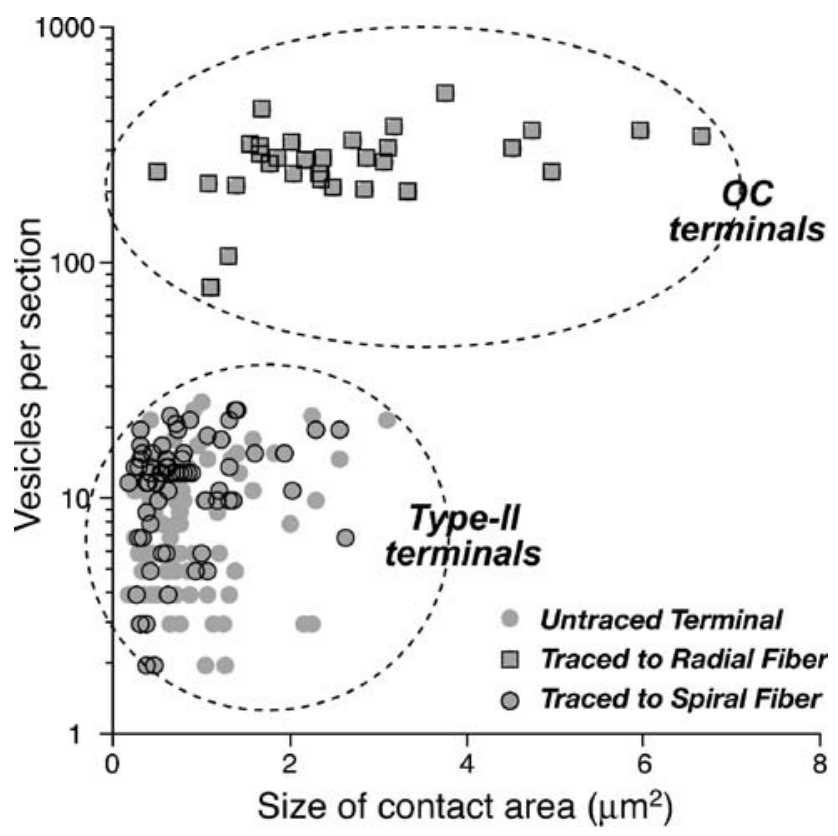

FIG. 3. Morphometry from serial sections shows that terminals contacting OHCs fall into two groups: small, vesicle-poor terminals generated by spiraling dendrites (type-Il terminals) and large vesiclerich swellings traced to radially projecting dendrites (OC terminals). This dataset represents terminals $(n=258)$ from a longitudinal-plane, serial-section series through $18 \mathrm{OHCs}$ from all three rows in the $0.7-\mathrm{kHz}$ region. For each terminal, the membrane apposition and vesicle count was measured from en face reconstructions of their contact area. Contact area was defined as the region for which the synaptic cleft was $<35 \mathrm{~nm}$. Synaptic vesicles were defined as any roughly circular membranous structure of diameter 35-100 nm within $140 \mathrm{~nm}$ of the zone of apposition.

terminals and OHCs (Nadol 1981; Thiers et al. 2002b). These synapses included, at the zone of apposition, both (1) an afferent specialization, characterized by modest pre- and post-synaptic membrane thickenings and a small cluster of pre-synaptic vesicles in the OHC, with or without a synaptic ribbon; and (2) an efferent specialization characterized by a flattened subsynaptic cistern within the OHC, similar to that seen opposite olivocochlear terminals (Fig. 2A), a modest degree of pre- and post-synaptic membrane thickening and a small cluster of pre-synaptic vesicles within the type-II terminal.

We found a similar type of reciprocal synapse at contacts between type-II terminals and OHCs throughout the cat cochlea. The micrographs in Figure 5 illustrate one such reciprocal synapse from the $0.7-\mathrm{kHz}$ region of a cat. In one section through this type-II terminal (Fig. 5A), there is a classic afferent synapse characterized by pre- and post-synaptic membrane specialization and a small cluster of pre-synaptic vesicles: Pre-synaptic ribbons are rare in the cat cochlea (Dunn and Morest 1975). In a subsequent section through the same terminal (Fig. 5B), there is an efferent specialization characterized by a small cluster of vesicles within 

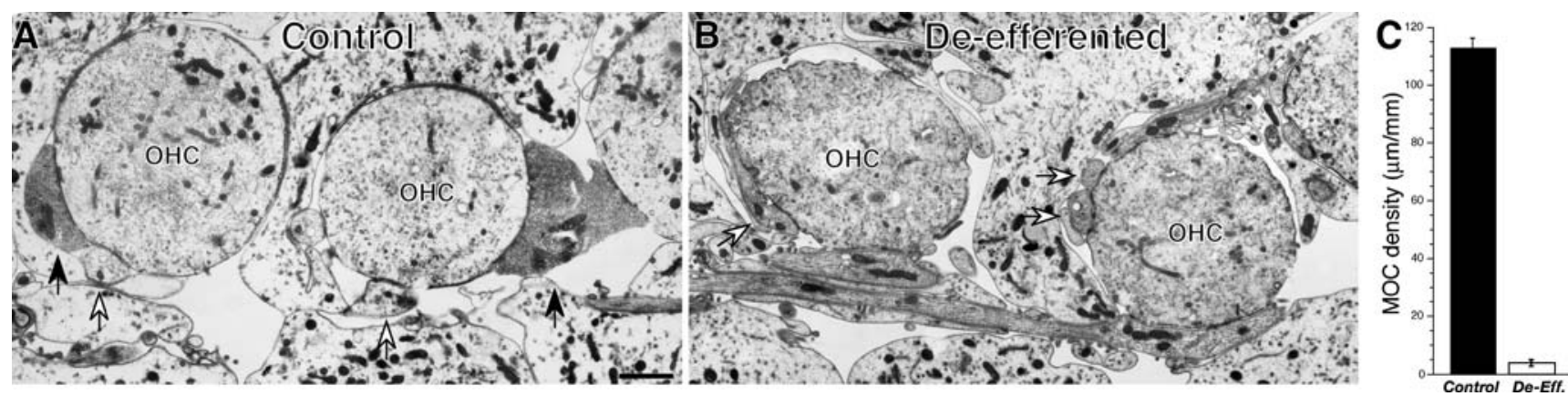

FIG. 4. After surgical section of the olivocochlear bundle, all large vesicle-rich terminals disappear, but small vesicle-poor terminals with reciprocal synapses remain. A Synaptic pole of two second-row $\mathrm{OHCs}$ from the $1.3-\mathrm{kHz}$ region of a normal adult cat. OC terminals are indicated by filled arrows. B Synaptic pole of two second-row $\mathrm{OHCs}$ from the $1.0-\mathrm{kHz}$ region of a surgically de-efferented cat, case

the type-II terminal and a distinct subsynaptic cistern within the OHC. As described by previous studies, typeII terminals frequently invaginate the $\mathrm{OHC}$ at the zone of apposition (Fig. 5), thereby increasing the surface area of contact.

A comprehensive analysis of all type-II terminals innervating a group of 18 neighboring OHCs from the $0.7-\mathrm{kHz}$ region was undertaken from a complete serialsection series. We selected the $0.7-\mathrm{kHz}$ region because analyses in chimpanzee (Francis and Nadol 1993) showed more reciprocal synapses in the apical half of the cochlea. A type of en face reconstruction was used to estimate the relative surface area of afferent and efferent specializations at each zone of apposition between a type-II terminal and an OHC (Fig. 5C). The great majority of type-II terminals in the $0.7-\mathrm{kHz}$ region $(86 \%)$ had reciprocal synapses; however, there were varying ratios of afferent vs. efferent specialization. Some of the smallest type-II terminals were $100 \%$ afferent or
93042L (Liberman et al. 2000). Remaining type-Il terminals are indicated by open arrows. Section plane in both cases was horizontal. C Mean density of MOC tunnel-crossing fascicles $( \pm$ SEM) averaged over the $1-24-\mathrm{kHz}$ regions from control ears vs. the de-efferented case, 93042L: Data from a previous study (Liberman et al. 2000).

$100 \%$ efferent; however, the type-II terminals with the largest zones of apposition were invariably reciprocal (Fig. 6A). Counts of pre-synaptic vesicles, defined as approximately circular membranous objects within $140 \mathrm{~nm}$ of the membrane, revealed an average of 19.0 vesicles/ $\mu \mathrm{m}^{2}(\mathrm{SEM}=1.55)$ for efferent specializations vs. 61.8 vesicles $/ \mu \mathrm{m}^{2}(\mathrm{SEM}=2.22)$ for afferent specializations: Differences were significant $(p<0.0001)$ by $t$ test.

Reciprocal synapses were found among type-II contacts on all three rows of OHCs. As shown in Figure 6B, which displays the afferent/efferent ratio for each terminal, arrayed in 18 columns to represent the 18 hair cells reconstructed, the efferent components of the reciprocal synapses were slightly more common on thirdrow OHCs. It may be significant, in this regard, that third-row OHCs in this cochlear region in cat also receive far fewer classic efferent synapses from OC terminals (Liberman et al. 1990 and data from this study not shown).
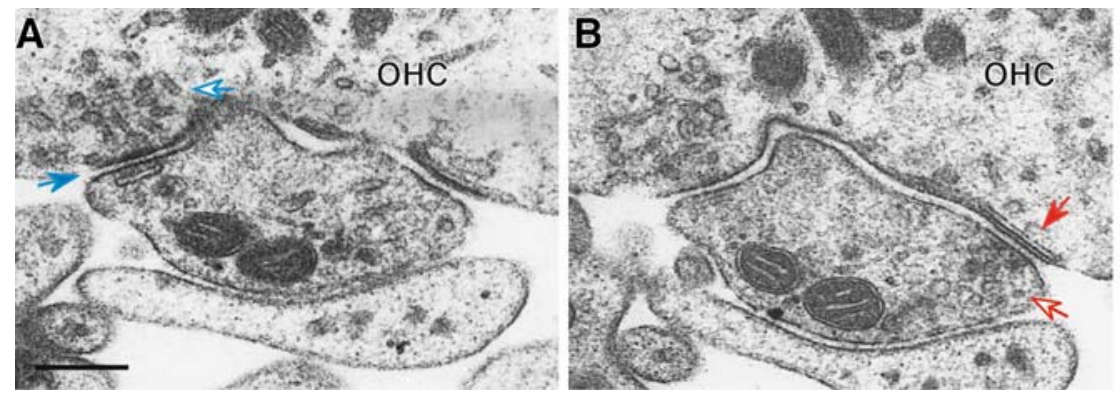

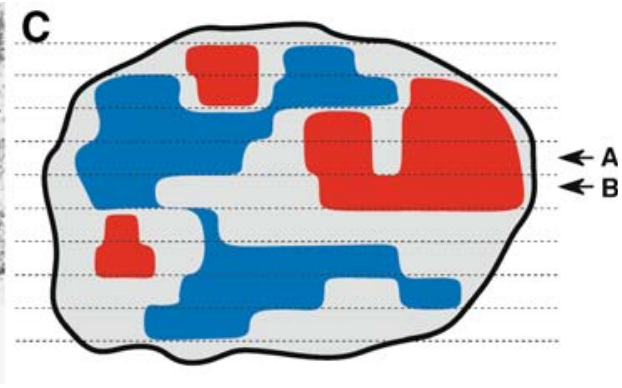

FIG. 5. Terminals from type-II neurons give rise to both afferent and efferent specializations in a reciprocal synapse with the OHC. A, B Adjacent sections through a reciprocal synapse. Scale bar=0.25 $\mu \mathrm{m}$. Pre-synaptic vesicles in $\mathbf{A}$ and $\mathbf{B}$ are indicated by unfilled arrows in the $\mathrm{OHC}$ and type-II terminal respectively. C En face reconstruction of afferent (b/ue) and efferent (red) specializations within the contact zone for this terminal are shown, and the positions of sections $\mathbf{A}$ and $\mathbf{B}$ are indicated. Afferent synaptic specialization was defined as a continuous (observed in at least two adjacent serial sections) pre- and post-synaptic membrane condensation in the area of apposition with corresponding narrowing of the synaptic cleft and with a cluster of small vesicles (35-100 nm diameter) within $140 \mathrm{~nm}$ of the hair cell membrane. Efferent synaptic specialization was defined by the presence of a subsynaptic cistern in the $\mathrm{OHC}$, i.e., a flattened membranous sac with one side $<15 \mathrm{~nm}$ from the zone of apposition in at least two adjacent serial sections and the presence of small vesicles within $140 \mathrm{~nm}$ of the terminal membrane. 

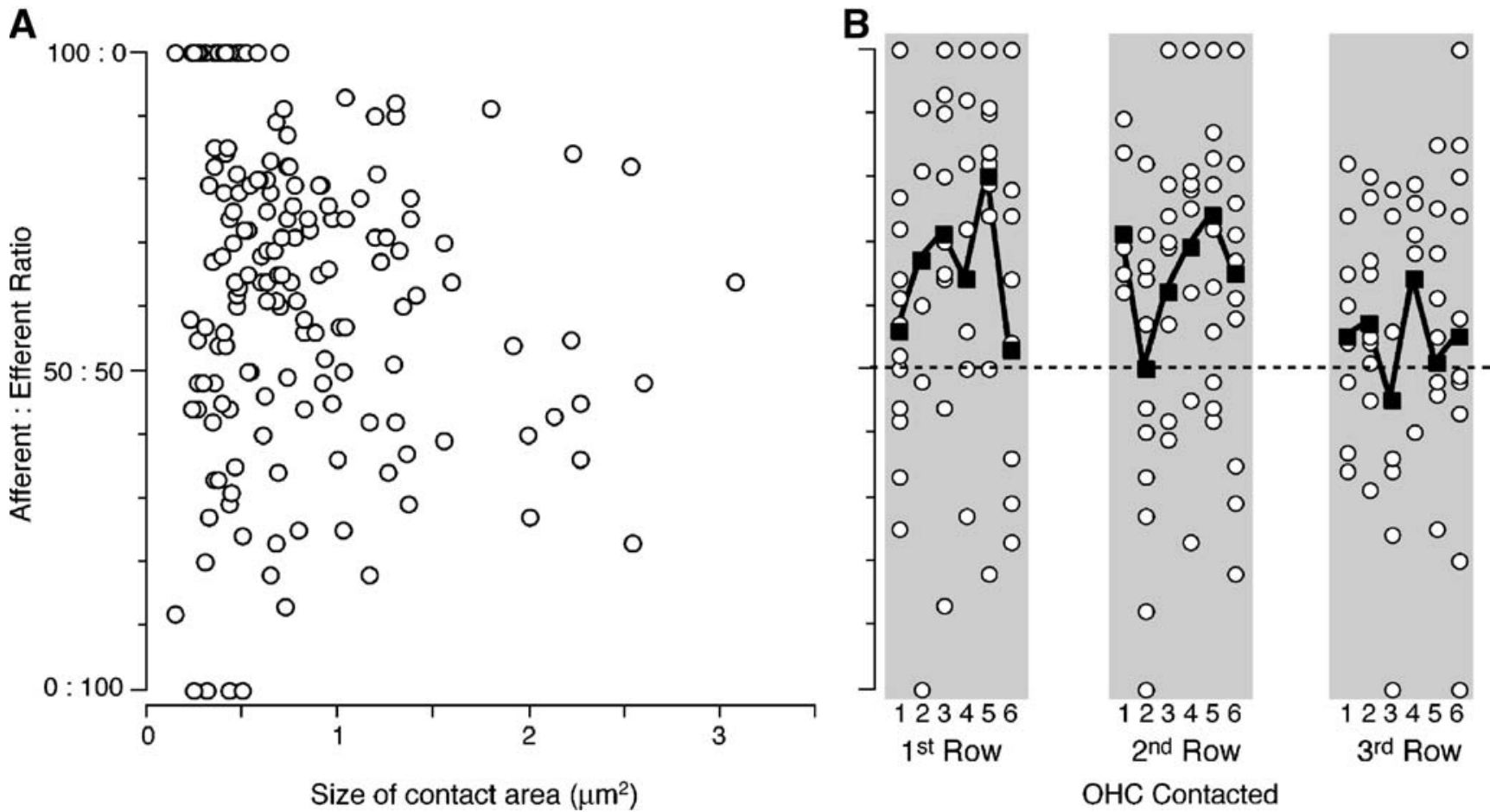

FIG. 6. Efferent specializations are seen on type-Il terminals of all sizes (A) and from every $\mathrm{OHC}$ in all three rows (B). A Ratio of afferent/efferent specialization area, defined as in Figure 5, for each type-Il terminal, plotted vs. its total contact area, computed as shown in Figure 3. B Ratio of afferent/efferent specialization areas for each type-Il terminal organized by hair cell, one column per cell. The

To assess the generalizability of the data on reciprocal synapses from the $0.7-\mathrm{kHz}$ region, we next examined (1) a cochlear region about one octave higher in frequency $(1.6 \mathrm{kHz})$ from the same animal (MCL94L) and (2) six log-frequency-spaced cochlear regions $(0.35$ to $12 \mathrm{kHz})$ from a different animal (MCL109L). To streamline the analysis, micrographs were obtained only from every fifth section; thus, the fraction of terminals showing reciprocal synapses is lower, e.g., $\sim 60 \%$ in the $0.73-\mathrm{kHz}$ region in the semiserial analysis vs. $86 \%$ in the $0.7-\mathrm{kHz}$ serial-section analysis. Considering only the relative frequency as a function of cochlear location (Fig. 7A), the proportion of type-II terminals showing reciprocal synapses is higher in the apical half than in the basal half of the cochlea, as reported for the chimpanzee (Francis and Nadol 1993).

To further verify the type-II origin of these reciprocal terminals, we examined semi-serial sections (every fifth) through five second-row OHCs from the $1.0-\mathrm{kHz}$ region of the de-efferented cat described above. Indeed, as shown in Figure 7A, the fraction of terminals with reciprocal synapses was similar in the chronically de-efferented ear to that seen in the corresponding regions of two different normal ears. filled squares show the mean ratio for each $\mathrm{OHC}$ (numbered 1-6 from apex to base within the tissue block). Data for both panels are from serial sections through $18 \mathrm{OHCs}$ in the $0.7-\mathrm{kHz}$ region. Terminals with two or fewer informative sections $(53 \%$ of the terminals) were excluded from these plots.

Reciprocal circuits formed by type-II fibers

The complete serial-section montages of six OHCs from each row (from the $0.7-\mathrm{kHz}$ region of the normal ear, MCL94L) provided the opportunity to trace connectivity patterns among terminals emanating from single type-II fibers and thereby reveal the opportunities for local intercommunication provided by this network of reciprocal synapses in the OHC area. Light-microscopic studies of HRP-filled type-II peripheral dendrites in cat showed little branching of these spiraling fibers in the outer spiral bundles, beyond the tiny terminal branchlets feeding each terminal swelling (Simmons and Liberman 1988a). Thus, each of the 30 spiraling fibers (see Fig. 8A,B) that we partially reconstructed in the outer spiral bundles probably represents a segment of the terminal field of a different type-II spiral ganglion cell.

The schematic in Figure 8C summarizes this local neuronal circuitry under these 18 OHCs. Salient points are (1) all type-II fibers make reciprocal synapses with multiple OHCs, (2) the ratios of afferent/efferent specialization are randomly distributed across type-II fibers, and (3) if reciprocal synapses enable bidirectional communication between OHCs and type-IIs, the local neural network under the OHCs provides a robust vehicle for intercommunication among OHCs. 


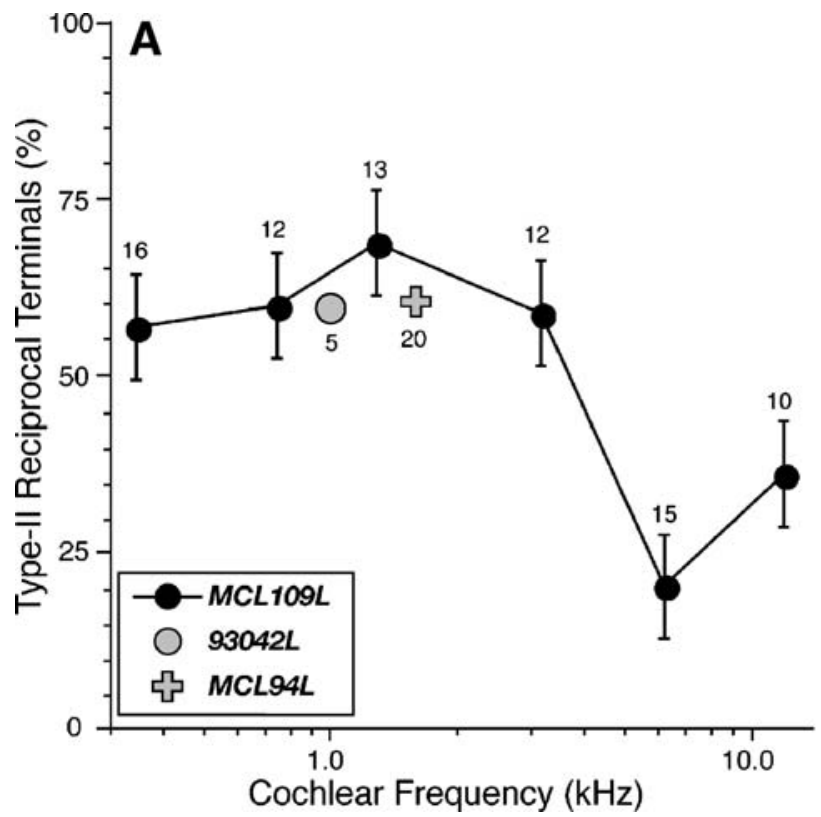

FIG. 7. Type-II terminals with reciprocal synapses are found throughout the cochlear spiral, and their numbers are not affected by complete cochlear de-efferentation. A Mean percentage of type-II terminals $( \pm$ SEM) with reciprocal synapses (i.e., afferent plus efferent specializations) as a function of cochlear location. Three data sets are shown: (1) semi-serial (every fifth) horizontal-plane sections through at least ten $\mathrm{OHCs}$ from all three rows in each of six cochlear regions from a normal cat (MCL109L); (2) a surgically de-efferented

\section{OC synapses onto type-II fibers and terminals}

Previous ultrastructural studies have described synapses from large, vesicle-filled terminals (presumably of OC

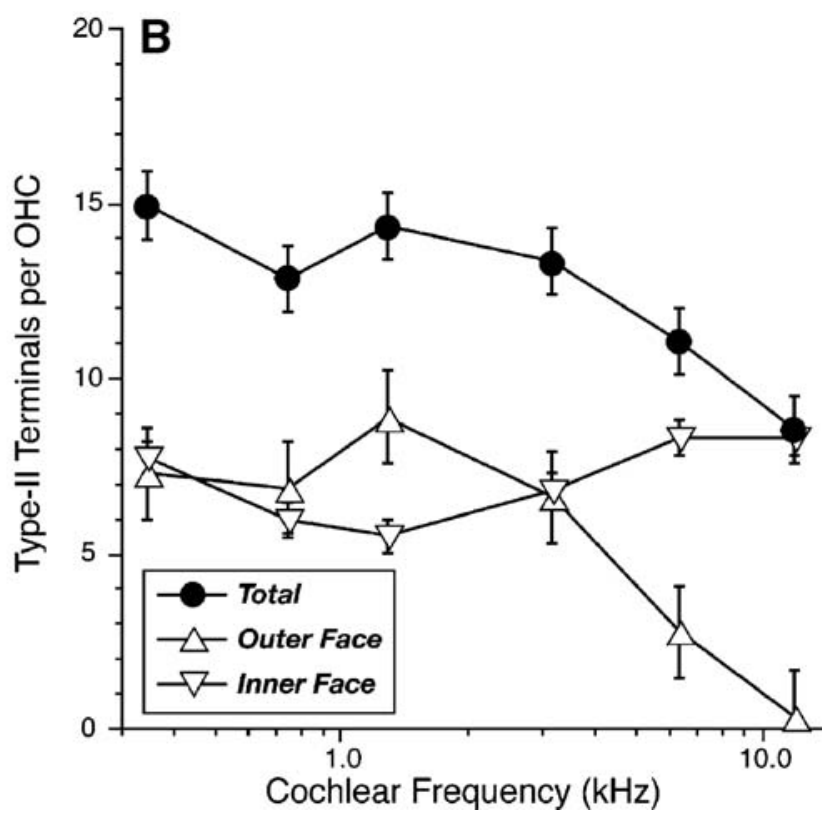

cat (93042L: Fig. 4) in which semi-serial sections (every fifth) were analyzed through five OHCs from the second row in the $1-\mathrm{kHz}$ region; and (3) semi-serial sections through $20 \mathrm{OHCs}$ from third row in the $1.6-\mathrm{kHz}$ region. The number of OHCs analyzed is indicated near each point. B Mean number of type-II terminals $( \pm$ SEM) per $\mathrm{OHC}$ from the same multi-region dataset shown in $\mathbf{A}$, with the data further subdivided (open symbols) into terminals on the inner (modiolar) vs. outer (strial) side of the $\mathrm{OHC}$.

origin) onto small (presumed type-II) terminals under OHCs and/or onto the neurotubule-rich presumed dendrites of type-II fibers in the outer spiral bundles (Thiers et al. 2002a) or in the tunnel of Corti (Liberman
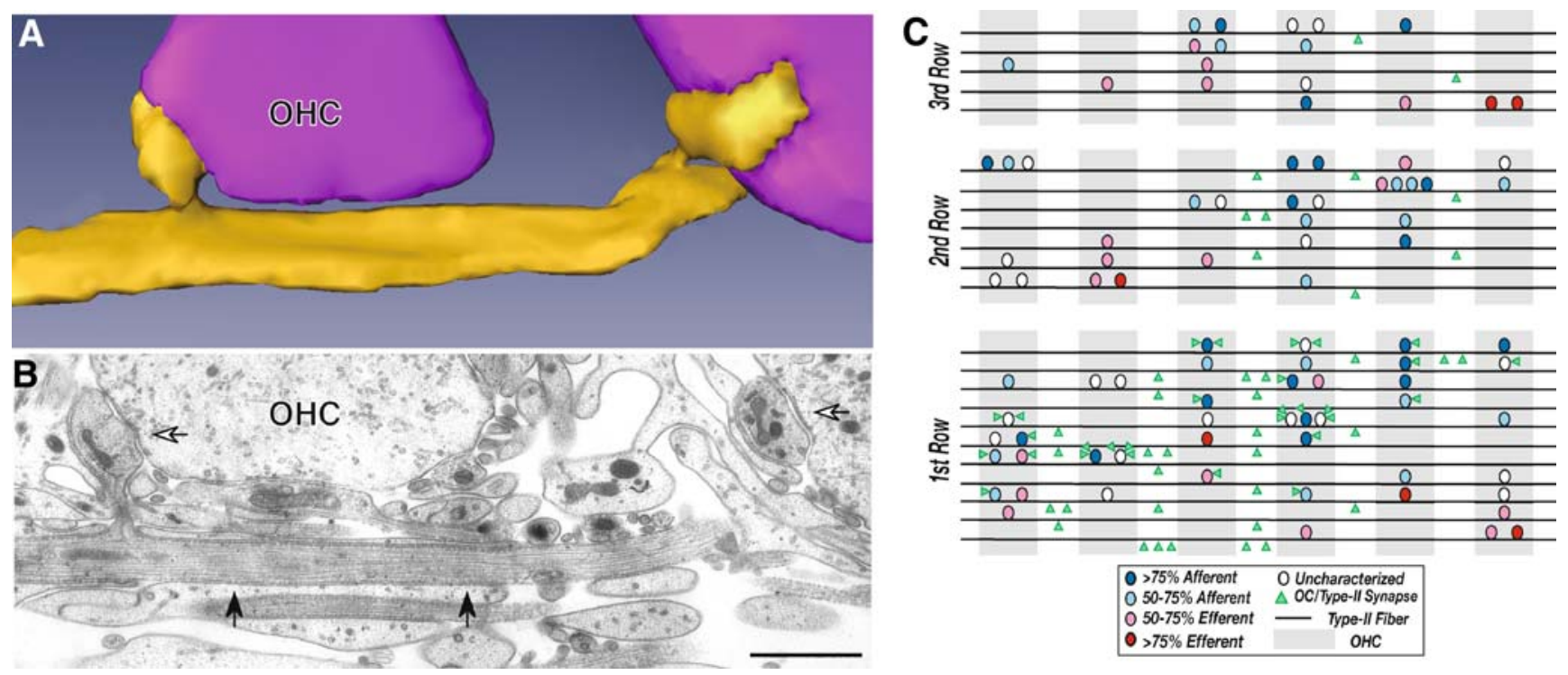

FIG. 8. All type-Il fibers have terminals with reciprocal synapses and are innervated by OC fibers. A Three-dimensional reconstruction of two terminals from the same parent fiber. B One section from the reconstruction in $\mathbf{A}$ illustrating two terminals with reciprocal synapses (unfilled arrows) from one spiral fiber (filled arrows) contacting a neighboring pair of third-row OHCs. Scale $=1 \mu \mathrm{m}$. C Schematic of the afferent/efferent specialization ratios (color-coded as shown in the key) on each terminal traced to one of the 23 spiraling type-Il fibers in the serial-section dataset from the $0.7-\mathrm{kHz}$ region. Locations of OC synapses on the type-II fibers or terminals are schematized by green arrowheads. 
1980a). However, previous studies have provided little insight into the prevalence of this type of synaptic interaction.

The richness of the OC/type-II projections is schematized in Figure 8C. A total of 216 OC/type-II synapses were noted in this serial-section analysis of the $0.7-\mathrm{kHz}$ region of MCL94L. As quantified in Figure 9, OC/typeII synapses were most common near first-row OHCs, where about half targeted spiraling dendrites and half targeted type-II terminals (or their terminal branchlets). The strong radial gradient (Fig. 9B) reflects a similar gradient in the density of OC innervation to the three OHC rows (Liberman et al. 1990). Interestingly, OC/type-II synapses tended to preferentially target type-II terminals with more afferent specialization in their reciprocal contacts with OHCs (Fig. 9A).

\section{DISCUSSION}

\section{Ultrastructural studies of $\mathrm{OHC}$ synaptic morphology}

Reciprocal synapses. Morphological signs of bidirectional signaling between hair cells and their sensory neurons have been reported in other systems and in a range of species. Reciprocal synapses have been found on IHCs in mouse, both in adult ears (Sobkowicz et al. 2003) and in cultured neurons reinnervating cochlear explants (Sobkowicz et al. 1993). They have also been reported between afferent neurons and hair cells of the vestibular macula in rat (Ross 1997), crista ampullaris in chinchilla (Lysakowski and Goldberg 1997), crista ampullaris in bullfrog (Dunn 1980), and the paratympanic organ in chicken (Giannessi 1989).

Reciprocal synapses in the OHC area were first reported in a serial-section ultrastructural study of an adult human cochlea (Nadol 1981) and then confirmed in a chimpanzee (Francis and Nadol 1993) and a human infant (Thiers et al. 2002b). The pattern of reciprocal synapses observed in primates was similar to that observed here in cat. All studies note an increased prevalence in apical vs. basal halves of the cochlea and among third-row vs. first-row OHCs, i.e., in gradients complementary to that for innervation of OHCs by terminals of olivocochlear efferents (Liberman et al. 1990), the other source of terminals in the OHC area.

Prior studies in primates relied on circumstantial evidence that the small, vesicle-poor terminals making reciprocal synapses with OHCs arise from peripheral dendrites of type-II neurons. Here, we provide more direct evidence by demonstrating a similar prevalence of reciprocal synapses in an ear after surgical transection of the OC bundle. Prior studies in guinea pig (Jones and Eslami 1983) and cat (Ginzberg and Morest 1983,
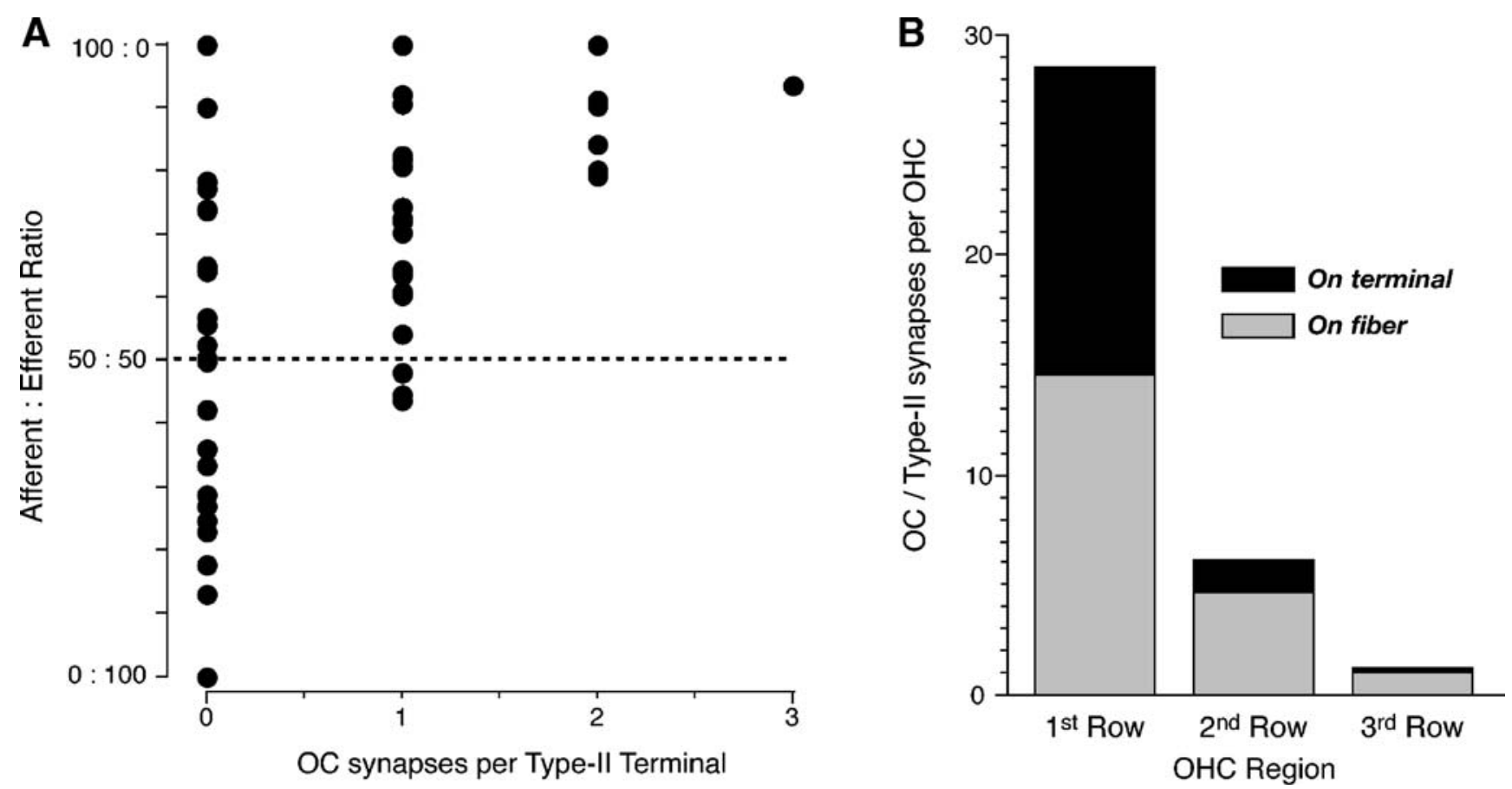

FIG. 9. OC synapses on type-Ils are more common on terminals with more afferent specialization $(\mathbf{A})$ and are more common in the first row of OHCs (B), where the density of OC terminals is greatest. A Ratio of afferent/efferent specialization, defined as in Figure 5, plotted vs. the number of synaptic contacts from OC terminals. B Average number of $\mathrm{OC}$ synapses on type-Il terminals or fibers in the region of each $\mathrm{OHC}$ row, expressed per $\mathrm{OHC}$ width. Data for both panels are from serial sections through $18 \mathrm{OHCs}$ in the $0.7-\mathrm{kHz}$ region. 
1984; Simmons and Liberman 1988b) noted efferent specializations (e.g., a subsynaptic cistern) at terminals which otherwise appeared to be afferent, i.e., small and vesicle poor. However, in the absence of serial-section analysis, they were viewed as curiosities or anomalies. Reciprocal synapses between type-II terminals and OHCs were reported in both chinchilla (Iurato et al. 1978) and cat (Pujol and Carlier 1982) after cutting the OC bundle, just as seen here. However, the finding in both cases was interpreted as pathological, although thorough comparisons with control ears were not presented. Other de-efferentation studies have reported survival of efferent specializations in the OHC area (Smith and Rasmussen 1963; Spoendlin and Gacek 1963; Nakai and Igarashi 1974; Morrison et al. 1975); however, without systematic analysis of terminal morphology and independent assessment of the degree of de-efferentation, it is difficult to separate effects of incomplete OC removal from the presence of type-II reciprocal synapses.

At the ultrastructural level, both afferent and efferent specializations at the type-II synapses are relatively modest, with small numbers of pre-synaptic vesicles. Combined with the lack of myelination of type-II axons, the morphology suggests a relatively slow response. Previous ultrastructural studies noted the paucity of presynaptic ribbons at the OHC/type-II synapse, as compared to the IHC/type-I synapse: in cat (Dunn and Morest 1975; Liberman et al. 1990) and guinea pig (Hashimoto et al. 1991), fewer than $10 \%$ or $30 \%$, respectively, of $\mathrm{OHC}$ synapses show ribbons in the adult, compared to $90-100 \%$ in IHCs (Liberman 1980b; Stamataki et al. 2006), where their presence enhances temporal precision and increases response rates in type-I fibers (Buran et al. 2006) and soundevoked cochlear gross potentials (Khimich et al. 2005). Data from the older ultrastructural studies are supported by more recent immunolabeling of synaptic ribbons with antibodies against CtBP2 (Khimich et al. 2005). Confocal immunohistochemistry in mouse cochleas has shown 15-20 synaptic ribbons per IHC vs. only about one to two per OHC (see Fig. 10).

OC/type-II synapses. A major peripheral target of the medial OC pathway are OHCs, where cholinergic signaling through $\alpha 9 / \alpha 10$ nicotinic receptors (Vetter et al. 2007) and the resultant decrease in OHC contribution to cochlear amplification have been well studied (Guinan 1996). Previous ultrastructural studies have described synapses from vesicle-rich, presumably OC, terminals onto type-II neurons. In primates, such synapses have been seen in the spiral ganglion onto type-II somata (Kimura et al. 1987; Thiers et al. 2000). In cat, such synapses have been noted in the tunnel of Corti (Liberman 1980a), and in cat, chinchilla, and primate, they have been described in the outer spiral

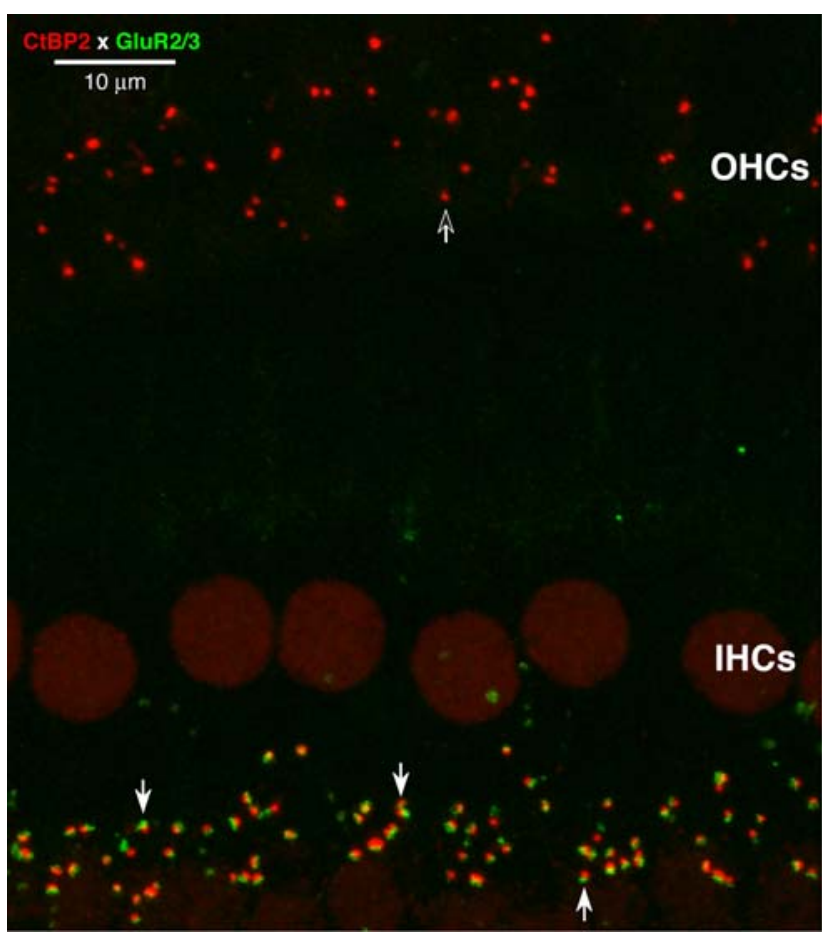

FIG. 10. Confocal image from the apical turn of a mouse cochlea immunostained for AMPA-type glutamate receptors (anti-GluR2/3, green) and synaptic ribbons (anti-CtBP2, red) shows colocalization at synapses in the IHC area (solid arrows) and lack of AMPA-type glutamate receptors in the $\mathrm{OHC}$ area (open arrow). The image is an $x y$ projection of a confocal z-stack spanning the subnuclear synaptic zones of six adjacent IHCs and the corresponding seven to eight $\mathrm{OHCs}$ in each of the three rows

bundles (Iurato et al. 1978; Ginzberg and Morest 1984; Nadol and Burgess 1990).

Few previous studies have described the prevalence of such contacts, and their existence is often overlooked when considering peripheral effects of activating the OC system (but see Maison et al. 2007a). In the apical half of the cat cochlea, an average of $\sim 30$ such synapses were seen under each first-row $\mathrm{OHC}$, on either the type-II terminals themselves or their terminal branchlets (Fig. 9C). Given that OC innervation density grows towards the base (Liberman et al. 1990), the prevalence of such OC/type-II contacts may also increase dramatically in higher frequency regions.

Cochlear neurons do not express $\alpha 9$ or $\alpha 10$ but do express a number of other nicotinic ACh receptors including $\alpha 7$ and $\beta 2$ (Bao et al. 2005), which could mediate cholinergic signaling at these synapses; GABAergic transmission also must be considered, given evidence for $\mathrm{GABA}$ in $\mathrm{OC}$ terminals in the $\mathrm{OHC}$ area (Maison et al. 2006) and for $\mathrm{GABA}_{\mathrm{B}}$ receptors in type-II terminals (Maison et al. 2007b). Regardless of the transmitters and receptors involved, the prevalence of the OC/type-II synapses and OHC/ type-II reciprocal synapses provides the hardware for 
complex local neural processing in the $\mathrm{OHC}$ area of the mammalian ear.

\section{Type-II responses and synaptic transmission} at their reciprocal synapses

The peripheral process of each bipolar type-II neuron contacts up to 100 OHCs (Simmons and Liberman 1988a), typically within a single OHC row. The type-II central axon projects to the cochlear nucleus, where it bifurcates into ascending and descending branches, as do the type-Is (Brown et al. 1988). The spiraling fibers and terminal branchlets of type-IIs in the organ of Corti are immunopositive for the $\mathrm{Na}^{+}$channels (Nav1.6), required to generate and propagate action potentials (Hossain et al. 2005). However, the peripheral and central axons of type-II neurons remain unmyelinated from cochlea to cochlear nucleus (Brown et al. 1988) and constitute only $5-10 \%$ of the auditory nerve (Spoendlin 1972); thus, almost nothing is known about their response properties in vivo (Robertson et al. 1999).

Similarly, the transmitters and receptors involved at the OHC/type-II synapse are not well understood, even for the afferent component. Immunohistochemistry shows voltage-gated calcium channels (Cav1.3) at the basal pole of adult OHCs, and voltage-dependent calcium currents have been measured in isolated OHCs at least as late as P30 (Knirsch et al. 2007). Immature OHCs (at P3) show capacitance changes elicited by voltage steps, consistent with vesicle release (Beurg et al. 2008). Thus, conventional synaptic transmission may take place at the OHC/type-II contact. There is ample pharmacological evidence that IHC/type-I synapses are glutamatergic and that type-I terminals express AMPAtype receptors (Ruel et al. 2007). In vitro, neonatal typeIIs show a glutamate response that is enhanced by cyclothiazide (Jagger and Housley 2003), consistent with AMPA-type transmission; however, this response appears to be from somatic receptors and may represent a transient developmental stage. In the adult, immunoelectron microscopic studies fail to show glutamate receptors at the type-II synapse (Matsubara et al. 1996), and the prominent excitotoxic response elicited at the IHC/type-I synapse after cochlear perfusion of glutamate agonists is absent in the $\mathrm{OHC}$ area (Pujol and Puel 1999). Immunohistochemistry in adult mouse cochleas confirms that AMPA-type glutamate receptors colocalize with synaptic ribbons in the IHC area but are absent in the OHC area (Fig. 10).

Transmitter(s) and receptor(s) at the efferent component of the reciprocal synapse are completely unknown. The subsynaptic cistern at the type-II reciprocal synapse appears identical to that opposite OC terminals on OHCs. This membranous sac, along with ryanodine receptors, has been implicated in calcium-induced calcium release underlying slow-onset, long-lasting suppressive effects of activating the OC bundle (Sridhar et al. 1997; Lioudyno et al. 2004). Thus, similar mechanisms may be at play here; indeed, some of the OCevoked slow effects could involve interactions mediated via the OC/type-II synapse and the OHC/type-II reciprocal synapse.

Reciprocal synapses or reciprocal circuits have been well studied in the olfactory bulb (Chen et al. 2000) and retina (Vigh and von Gersdorff 2005), respectively. In both these systems, there is evidence for glutamatergic transmission via NMDA receptors on the afferent side coupled with GABAergic transmission via $\mathrm{GABA}_{\mathrm{A}}$ and/ or $\mathrm{GABA}_{\mathrm{C}}$ receptors. NMDA receptors are present in the cochlea (Niedsielski and Wenthold 1995): At the IHC/type-I synapse, they have been implicated in the excitotoxic response (Puel et al. 1994). However, it is not clear whether type-II neurons also express NMDA receptors. There is strong evidence for GABAergic transmission in the $\mathrm{OHC}$ area, particularly the involvement of $\mathrm{GABA}_{\mathrm{A}}$ receptors (Maison et al. 2006); and targeted deletion of either $\alpha 5$ or $\beta 2 \mathrm{GABA}_{\mathrm{A}}$ subunits is associated with cochlear threshold shifts consistent with OHC dysfunction. Thus, it is possible that the type-II reciprocal synapses also couple glutamatergic excitation and GABAergic inhibition.

Significance of local neural circuits in the $\mathrm{OHC}$ area

If viewed as a sensory neuron, the functional role of the type-IIs lies only in the contributions of their central projections to brainstem circuitry. If viewed as a local neural circuit, with reciprocal synapses that mediate local feedback control and/or communication among neighboring OHCs, the functional significance of the type-II system takes on an added dimension, i.e., modulation of normal OHC function. The contribution of OHCs to cochlear threshold sensitivity requires their somatic electromotility, which is driven in vivo by receptor potentials produced by the OHC's stereociliary bundle (Dallos et al. 2006). Proper function of this cochlear amplifier presumably requires the coordinated action of neighboring groups of OHCs near the peak of the traveling wave, as well as precise control of stereociliary operating points to optimize the potentials driving somatic motors. It has been proposed that the OC system provides such feedback (LePage 1989); however, maintenance of normal threshold sensitivity and sharpness of neural tuning after complete deefferentation of the adult ear effectively rules out that hypothesis (Liberman 1990). The local neural circuitry of the type-II system could also perform such feedback, i.e., controlling and coordinating the resting position of neighboring OHCs, without involving the central nervous system or its descending projection to OHCs. 
Consistent with a role in fine-tuning of cochlear micromechanics, type-II neurons in the apical half of the cochlea branch profusely among Hensen's cells (Fechner et al. 1999), where their terminals form synapses that appear efferent (Burgess et al. 1997). Hensen's cells create a flying buttress at the outer edge of the reticular lamina, and, thus, are in a position to influence the tilt of the OHC hair bundles. Indeed, in an in vitro study of the guinea pig apical turn, overstimulation-induced collapse and reformation of the Hensen-cell arch correlated with attenuation and recovery, respectively, of hair cell receptor potentials (Flock et al. 1999).

There is no post-natal animal model of selective typeII loss; thus, we do not know if normal cochlear sensitivity requires this local neural circuitry under the OHCs. If type-II reciprocal circuits include a GABAergic component, as in the olfactory bulb (Chen et al. 2000), the OHC-based threshold shifts observed in mice lacking $\mathrm{GABA}_{\mathrm{A}}$ receptor subunits (Maison et al. 2006) could arise from a such a putative role of type-II circuits in maintaining cochlear sensitivity. The distortion component otoacoustic emission (DPOAE) at $f_{2}-f_{1}$ is particularly sensitive to the static position of the organ of Corti (Sirjani et al. 2004), and the $f_{2}-f_{1}$ DPOAE shows a slow amplitude change during continuous twotone stimulation, which can be blocked by bicucculine, a $\mathrm{GABA}_{\mathrm{A}}$ receptor antagonist (Kirk and Johnstone 1993). Previous studies have considered only the OC system as a source of GABAergic innervation of the OHCs; the present study suggests that the type-II system must be considered as well.

\section{ACKNOWLEDGEMENTS}

Research supported by grants from the NIDCD (RO1 DC 00188 and P30 DC05209 to MCL), from the National Organization for Hearing Research and the Hugh Hampton Young Memorial Fund (to FAT), and by a training fund for the Program in Speech and Hearing Science and Technology established by the Amelia Peabody Charitable Fund. The technical assistance of Barbara Burgess is gratefully acknowledged.

\section{REFERENCES}

Bao J, Lei D, Du Y, Ohlemiller KK, Beaudet AL, Role LW. Requirement of nicotinic acetylcholine receptor subunit beta2 in the maintenance of spiral ganglion neurons during aging. J. Neurosci. 25:3041-3045, 2005.

Beurg M, Safieddine S, Roux I, Bouleau Y, Petit C, Dulon D. Calcium- and otoferlin-dependent exocytosis by immature outer hair cells. J. Neurosci. 28:1798-1803, 2008.

BROWN MC. Morphology of labeled efferent fibers in the guinea pig cochlea. J. Comp. Neurol. 260:605-618, 1987a.

BRown MC. Morphology of labelled afferent fibers in the guinea pig cochlea. J. Comp. Neurol. 260:591-604, 1987b.
BRown MC. Antidromic responses of single units from the spiral ganglion. J. Neurophysiol. 71:1835-1847, 1994.

Brown MC, Berglund AM, Kiang NY, Ruggo DK. Central trajectories of type II spiral ganglion neurons. J. Comp. Neurol. 278:581-590, 1988.

Buran BN, Moser T, Gundelfinger E, Liberman MC. Role of synaptic ribbons in auditory nerve response: recordings from mice lacking the synaptic scaffolding protein bassoon. Abstracts of the Association for Research in Otolaryngology: XXIXth Midwinter Meeting 29:207, 2006.

Burgess BJ, Adams JC, NAdOL JB. Morphologic evidence for innervation of the Deiters and Hensen's cells in the guinea pig. Hear. Res. 108:74-82, 1997.

Chen WR, Xiong W, Shepherd GM. Analysis of relations between NMDA receptors and GABA release at olfactory bulb reciprocal synapses. Neuron. 25:625-633, 2000.

Dallos P, Fakler B. Prestin, a new type of motor protein. Nat. Rev. Mol. Cell. Biol. 3:104-111, 2002.

Dallos P, Zheng J, Cheatham MA. Prestin and the cochlear amplifier. J. Physiol. 576:37-42, 2006.

DunN RF. Reciprocal synapses between hair cells and first order afferent dendrites in the crista ampullaris of the bullfrog. J. Comp. Neurol. 193:255-264, 1980.

DunN RA, MOREST DK. Receptor synapses without synaptic ribbons in the cochlea of the cat. Proc. Natl. Acad. Sci. USA. 72:3599-3603, 1975.

Fechner FP, Burgess BJ, Adams JC, Liberman MC, Nadol JB. Dense innervation of the Dieters' and Hensen's cells persists after chronic de-efferentation of guinea pig cochleas. J. Comp. Neurol. 400:299309, 1999.

Flock A, Flock B, Fridberger A, Scarfone E, Ulfendahl M. Supporting cells contribute to control of hearing sensitivity. J. Neurosci. 19:4498-4507, 1999 .

Francis HW, Nadol JB, Jr. Patterns of innervation of outer hair cells in a chimpanzee: I. Afferent and reciprocal synapses. Hear. Res. 64:184-190, 1993.

GiANNESSI F. On the presence of reciprocal synapses in the paratympanic organ of the chicken. Anat. Embryol. (Berl). 180:175$178,1989$.

GinzBerg RD, MoRest DK. A study of cochlear innervation in the young cat with the Golgi method. Hear. Res. 10:227-246, 1983.

GinZBERG RD, Morest DK. Fine structure of cochlear innervation in the cat. Hear. Res. 14:109-127, 1984.

Guinan JJ. The physiology of olivocochlear efferents. In: Dallos PJ, Popper AN, Fay RR (eds) The Springer Verlag Handbook of Auditory Research: The Cochlea. New York, Springer, 1996.

Hashimoto S, Kimura RS. Computer-aided three-dimensional reconstruction and morphometry of the outer hair cells of the guinea pig cochlea. Acta. Otolaryngol. 103:64-74, 1987.

Hashimoto S, Kimura RS, Takasaka T. Computer-aided threedimensional reconstruction of the inner hair cells and their nerve endings in the guinea pig cochlea. Acta. Otolaryngol. 109:228-234, 1991.

Hossain WA, Antic SD, Yang Y, Rasband MN, Morest DK. Where is the spike generator of the cochlear nerve? Voltage-gated sodium channels in the mouse cochlea. J. Neurosci. 25:6857-6868, 2005.

iurato S, Smith CA, Eldredge DH, Henderson D, Carr C, Ueno Y, Cameron S, Richter R. Distribution of the crossed olivocochlear bundle in the chinchilla's cochlea. J. Comp. Neurol. 182:57-76, 1978.

JAGger DJ, Housley GD. Membrane properties of type II spiral ganglion neurones identified in a neonatal rat cochlear slice. J. Physiol. 552:525-533, 2003

JONES DG, EsLAMI H. An ultrastructural study of the development of afferent and efferent synapses on outer hair cells of the guinea pig organ of Corti. Cell. Tissue Res. 231:533-549, 1983.

Khimich D, Nouvian R, Pujol R, Tom Dieck S, Egner A, Gundelfinger ED, Moser T. Hair cell synaptic ribbons are essential for synchronous auditory signalling. Nature. 434:889-894, 2005. 
Kiang NY, Rho JM, Northrop CC, Liberman MC, Ryugo DK. Hair-cell innervation by spiral ganglion cells in adult cats. Science. 217:175-177, 1982.

Kimura RS, Wersall J. Termination of the olivocochlear efferent bundle on in relation to the outer hair cells of the organ of Corti in guinea pig. Acta. Otolaryngol. 55:11-32, 1962.

Kimura RS, Bongiorno CL, Iverson NA. Synapses and ephapses in the spiral ganglion. Acta. Otolaryngol. Suppl. 438:1-18, 1987.

KIRK DL, Johnstone BM. Modulation of f2-f1: evidence for a GABAergic efferent system in apical cochlea of the guinea pig. Hear. Res. 67:20-34, 1993.

Knirsch M, Brandt N, Braig C, Kunn S, Hirt B, Munkner S, Knipper M, Engel J. Persistence of $\mathrm{Ca}(\mathrm{v}) 1.3 \mathrm{Ca} 2+$ channels in mature outer hair cells supports outer hair cell afferent signaling. J. Neurosci. 27:6442-6451, 2007.

LePage EL. Functional role of the olivo-cochlear bundle: a motor unit control system in the mammalian cochlea. Hear. Res. 38:178-198, 1989.

Liberman MC. Auditory-nerve response from cats raised in a lownoise chamber. J. Acoust. Soc. Am. 63:442-455, 1978.

LiBERMAN MC. Efferent synapses in the inner hair cell area of the cat cochlea: an electron microscopic study of serial sections. Hear. Res. 3:189-204, 1980a.

LibERMAN MC. Morphological differences among radial afferent fibers in the cat cochlea: an electron-microscopic study of serial sections. Hear. Res. 3:45-63, 1980b.

Liberman MC. The cochlear frequency map for the cat: labeling auditory-nerve fibers of known characteristic frequency. J. Acoust. Soc. Am. 72(5):1441-1449, 1982.

Liberman MC. Effects of chronic cochlear de-efferentation on auditory-nerve response. Hear. Res. 49:209-224, 1990.

Liberman MC, BEIL DG. Hair cell condition and auditory nerve response in normal and noise-damaged cochleas. Acta. Otolaryngologica. 88:161-176, 1979.

Liberman MC, Brown MC. Physiology and anatomy of single olivocochlear neurons in the cat. Hear. Res. 24:17-36, 1986.

Liberman MC, GaO WY. Chronic cochlear de-efferentation and susceptibility to permanent acoustic injury. Hear. Res. 90:158168, 1995.

Liberman MC, Dodds LW, Pierce S. Afferent and efferent innervation of the cat cochlea: quantitative analysis with light and electron microscopy. J. Comp. Neurol. 301:443-460, 1990.

Liberman MC, O'Grady DF, Dodds LW, McGee J, Walsh EJ. Afferent innervation of outer and inner hair cells is normal in neonatally de-efferented cats. J. Comp. Neurol. 423:132-139, 2000.

Lioudyno M, Hiel H, Kong JH, Katz E, Waldman E, ParameshwaranIyer S, Glowatzki E, Fuchs PA. A "synaptoplasmic cistern" mediates rapid inhibition of cochlear hair cells. J. Neurosci. 24:11160-11164, 2004.

Lysakowski A, GoldBerg JM. A regional ultrastructural analysis of the cellular and synaptic architecture in the chinchilla cristae ampullares. J. Comp. Neurol. 389:419-443, 1997.

Maison SF, Rosahl TW, Homanics GE, Liberman MC. Functional role of GABAergic innervation of the cochlea: phenotypic analysis of mice lacking GABA(A) receptor subunits alpha 1, alpha 2, alpha 5, alpha 6, beta 2, beta 3, or delta. J. Neurosci. 26:10315-10326, 2006.

Maison SF, VetTer DE, Liberman MC. A novel effect of cochlear efferents: in vivo response enhancement does not require alpha9 cholinergic receptors. J Neurophysiol. 97:3269-3278, 2007a.

Maison SF, Gassman M, Bettler B, Liberman MC. Deletion of Gaba$\mathrm{B}$ (1) receptors from cochlear ganglion cells leads to threshold elevation and increased resistance to permanent acoustic injury. Abstracts of the ARO XXXth Midwinter Meeting, 2007b.
Matsubara A, Laake JH, Davanger S, Usami Si, Ottersen OP. Organization of AMPA receptor subunits at a glutamate synapse: quantitative immunogold analysis of hair cell synapses in the rat organ of Corti. J. Neurosci. 16:4457-4467, 1996.

Morrison D, Schindler RA, Wersall J. A quantitative analysis of the afferent innervation of the organ of corti in guinea pig. Acta. Otolaryngol. 79:11-23, 1975.

NADOL JB, JR. Reciprocal synapses at the base of outer hair cells in the organ of corti of man. Ann. Otol. Rhinol. Laryngol. 90:12$17,1981$.

NAdOL JB, JR, BuRgess BJ. Morphology of synapses at the base of hair cells in the organ of Corti of the chimpanzee. Ann. Otol. Rhinol. Laryngol. 99:215-220, 1990.

NakaI Y, Igarashi M. Distribution of the crossed olivo-cochlear bundle terminals in the squirrel-monkey cochlea. Acta. Otolaryngol. 77:393-404, 1974.

NiEdSIELSki AS, Wenthold RJ. Expression of AMPA kainate and NMDA receptor subunits in cochlear and vestibular ganglia. J. Neurosci. 15:2338-2353, 1995.

Puel JL, Pujol R, Tribillac F, Ladrech S, Eybalin M. Excitatory amino acid antagonists protect cochlear auditory neurons from excitotoxicity. J. Comp. Neurol. 341:241-256, 1994.

Pujol R, Carlier E. Cochlear synaptogenesis after sectioning the efferent bundle. Dev. Brain Res. 3:151-154, 1982.

Pujol R, Puel JL. Excitotoxicity, synaptic repair and functional recovery in the mammalian cochlea: a review of recent findings. Ann. NY Acad. Sci. 884:249-254, 1999.

Robertson D, Sellick PM, Patuzzi R. The continuing search for outer hair cell afferents in the guinea pig spiral ganglion. Hear. Res. 136:151-158, 1999.

Ross MD. Morphological evidence for local microcircuits in rat vestibular maculae. J. Comp. Neurol. 379:333-346, 1997.

Ruel J, Wang J, Rebillard G, Eybalin M, Lloyd R, Pujol R, Puel JL. Physiology, pharmacology and plasticity at the inner hair cell synaptic complex. Hear. Res. 227:19-27, 2007.

Simmons DD, Liberman MC. Afferent innervation of outer hair cells in adult cats: I. Light microscopic analysis of fibers labeled with horseradish peroxidase. J. Comp. Neurol. 270:132-144, 1988a.

Simmons DD, Liberman MC. Afferent innervation of outer hair cells in adult cats: II. Electron microscopic analysis of fibers labeled with horseradish peroxidase. J. Comp. Neurol. 270:145-154, 1988b.

Sirjani DB, Salt AN, Gill RM, Hale SA. The influence of transducer operating point on distortion generation in the cochlea. J. Acoust. Soc. Am. 115:1219-1229, 2004.

Sмith CA, Rasmussen GL. Recent observations on the olivocochlear bundle. Ann. Otol. Rhinol. Laryngol. 72:489-497, 1963.

Sobkowicz HM, Slapnick SM, August BK. Presynaptic fibres of spiral neurons and reciprocal synapses in the organ of Corti in culture. J. Neurocytol. 22:979-993, 1993.

Sobkowicz HM, Slapnick SM, August BK. Reciprocal synapses between inner hair cell spines and afferent dendrites in the organ of corti of the mouse. Synapse. 50:53-66, 2003.

Spoendlin HH. Innervation densities of the cochlea. Acta. Otolaryngol. 73:235-248, 1972.

SPOENDLIN HH, GACEK RR. Electronmicroscopic study of the efferent and afferent innervation of the organ of Corti in the cat. Ann. Otol. Rhinol. Laryngol. 72:661-685, 1963.

SRIDHAR TS, BRown MC, SEWELl WF. Unique postsynaptic signaling at the hair cell efferent synapse permits calcium to evoke changes on two time scales. J. Neurosci. 17:428-437, 1997.

Stamataki S, Francis HW, Lehar M, May BJ, Ryugo DK. Synaptic alterations at inner hair cells precede spiral ganglion cell loss in aging C57BL/6J mice. Hear. Res. 221:104-118, 2006. 
Thiers FA, Burgess BJ, Nadol JB, Jr. Prevalence and ultrastructural morphology of axosomatic synapses on spiral ganglion cells in humans of different ages. Hear. Res. 150:119-131, 2000.

Thiers FA, Burgess BJ, Nadol JB, Jr. Axodendritic and dendrodendritic synapses within outer spiral bundles in a human. Hear. Res. 164:97-104, 2002a.

Thiers FA, Burgess BJ, Nadol JB, JR. Reciprocal innervation of outer hair cells in a human infant. J. Assoc. Res. Otolaryngol. 3:269-278, 2002b.
Vetter De, Katz E, Maison SF, Taranda J, Turcan S, Ballestero J, Liberman MC, Elgoyhen AB, Boulter J. The alpha10 nicotinic acetylcholine receptor subunit is required for normal synaptic function and integrity of the olivocochlear system. Proc. Natl. Acad. Sci. USA. 104:20594-20599, 2007.

VIGH J, vON GERSDORfF H. Prolonged reciprocal signaling via NMDA and GABA receptors at a retinal ribbon synapse. J. Neurosci. 25:11412-11423, 2005. 